\title{
Efectividad según diferentes pautas de administración de hierro sacarosa intravenoso en pacientes en hemodiálisis. Estudio comparativo de dos pautas
}

\author{
Alicia Quintano Pintado, Ana Dorado García
}

Hospital Universitario Río Hortega. Valladolid

\section{Introducción:}

La anemia es la complicación más frecuente en la insuficiencia renal crónica. La evidencia demuestra que el hierro sacarosa (HS) intravenoso es altamente efectivo para este tipo de anemia con déficit de hierro; su corrección mejora la supervivencia, disminuye la morbilidad y aumenta la calidad de vida.

\section{Objetivo:}

Identificar la forma más eficaz de administrar hierro sacarosa intravenoso durante hemodiálisis comparando diferentes pautas de administración.

\section{Material y método:}

Estudio longitudinal comparativo experimental de un año. Criterios de inclusión: Pacientes estables en hemodiálisis y con HS intravenoso durante los dos periodos (semestres) en los que dividimos el estudio. Criterios de exclusión: Pacientes inestables que han requerido transfusiones durante el tiempo que ha durado el estudio. La dosis HS y los estimuladores de la eritropoyesis (EP0) varían según analítica bimensual. Periodo basal: Administración de una ampolla de HS de $100 \mathrm{mg}$ en $100 \mathrm{cc}$ de suero fisiológico en los últimos 30 minutos de la hemodiálisis a través de bomba de infusión. Primer grupo experimental: pacientes de lunes, miércoles, viernes; $100 \mathrm{mg}$ de HS disuelto en $5 \mathrm{cc}$ de suero fisiológico administrado a través de la bomba del monitor de hemodiálisis en la última hora de tratamiento, Segundo grupo experimental: pacientes de martes, jueves y sábado; $100 \mathrm{mg}$ de HS disuelto en $15 \mathrm{cc}$ de suero fisiológi- co y administrado a través de la bomba del monitor de hemodiálisis en las dos últimas horas de tratamiento, Comparamos los datos recogidos bimensualmente en el periodo basal con los datos recogidos en ambos periodos experimentales. Variables: Datos sociodemográficos, tiempo diálisis, hematocrito, hemoglobina, hematíes, ferritina, hierro, transferrina, saturación transferrina, dosis hierro, dosis EPO. El análisis estadístico se realizó con el programa SPSS 15.0 (Windows). Las variables cualitativas se expresaron en frecuencias y porcentajes, las cuantitativas como media y desviación típica. Se verificó que ambos grupos eran homogéneos y se aplicó la $T$ de Student para el contraste de muestras relacionadas.

\section{Resultados:}

Un total de 36 pacientes, el 66,7\% hombres, media de edad, 68 años. Analizado el periodo basal con el primer grupo experimental-100mg de HS disuelto en $5 \mathrm{cc}$ de suero fisiológico administrado a través de la bomba del monitor de hemodiálisis en la última hora de tratamiento- encontramos aumento del hematocrito $(p>0.039)$, hemoglobina $(p>0.02)$, hierro $(p>0.002)$, saturación de transferrina( $p>0.018)$; hematíes, transferrina y ferritina mejoraron sin significación estadística; disminuyó necesidad de dosis EPO ( $p>0.08)$ y dosis HS ( $p>0.029)$. Comparando el periodo basal con el segundo grupo experimental- $100 \mathrm{mg}$. de HS disuelto en $15 \mathrm{cc}$ de suero fisiológico y administrado a través de la bomba del monitor de HD en las dos últimas horas de tratamiento- aumentó hematocrito ( $p>0.038$ ) y transferrina $(p>0.01)$; $h$ emoglobina, hematíes y dosis EPO aumentan sin significación; ferritina, saturación de transferrina y dosis HS disminuyeron de la misma forma. 


\section{Conclusión:}

La administración a través de la bomba de heparina de HS durante una hora es más efectiva frente a la administración en dos horas y a la pauta basal de media hora. El impacto económico se reduce al disminuir el material fungible y el gasto farmacéutico. En ninguna pauta de administración aparecieron efectos adversos durante la administración.

\section{Referencias Bibliográficas}

1. Sánchez Sancho, M; Ridao, N; Valderrábano, F. El tratamiento médico del enfermo en Hemodiálisis. En: Valderrábano F. Trtado de hemodiálisis. BarceIona. Médica Jims; 1999:385-402.

2. Fernández Gallego, J.; Ramos, B.; Lopéz de Novales $\mathrm{E}$. Tratamiento con hierro intravenoso e infección en hemodiálisis. Rev. Nefrologia 2002; 1 (XXII): 89-90.

3. Alfaro Cuenca, A.; Gallego Jordán, B.; Martín Piñero, M.; Romero Espinosa, E.; Sidrach de Cardona García, V. ¿Influye la velocidad de administración de hierro sacarosa (venofer) en la ferrocinética en el paciente con IRC en hemodiálisis? Libro de comunicaciones del XXIX Congreso Nacional SEDEN 2004; 188-194.

4. Donado, E.; Aguasca, M.; Ocharan Corchera, J. Hierro sacarosa intravenoso en el paciente con enfermedad renal crónica. Dial traspl.2007;28(1):17-25.

5. López Gómez, JM.; Manejo de la anemia en la enfermedad renal crónica. Guía SEN. Nefrología 2008 Supl. 3, 63-66.

6. Brazález Tejerina, M.; Pérez Arranz, I; González Parra, E; Pose Regueiro, NM; Muñoz Moreno, MF.
Valoración de la eficacia de una pauta más lenta y frecuente en la administración de hierro intravenoso en pacientes en hemodiálisis durante un año. Enfermería Nefrológica 2012;15(1):63-65.

7. Siga, E.; Aiziczon, D.; Díaz, G. Optimización del tratamiento con hierro endovenoso en hemodiálisis estudio clínico prospectivo a largo plazo. Medicina (Buenos Aires) 2011;71:9-14.

8. Sánchez, L.; Del Pozo, C.; Torregrosa, I.; Albero, MD.; Lopéz-Menchero, R.; Ramos, JR.; Ferroterapia intravenosa en hemodiálisis: comparación de dos pautas de tratamiento. Nefrología 2001; 21 (supl 2):40.

9. Siga, E.; Aiziczon, D.; Díaz, G. Terapéutica con hierro sacarosa en nuestro medio: dosis y frecuencia adecuada. Resúmenes del XIV Congreso argentino de Nefrología 2005: 152.

10. National Kidney Foundation.KDOQI Clinical practice guide lines and clinical pradtice recommendations for anaemia in chronic kidney disease. AM j Kidney Dis 2006;47: S1-S145.

11. Minguela, JI.; Moraza, MA; Chena, A; Jimeno, I; Ocharan-Corcuera J.; Ruiz-de-Gauna, R. Administración de hierro intravenoso en la consulta de nefrología. Dial traspl. 2009; 30:8-10- vol. 30 num.01.

12. Lacueva Moya, J. ; Antolin-Cariñera, A.; Santamaría C.; Vicent-Bayarri C. Efectos Beneficiosos del paso de gluconato ferrico a hierro sacarosa sobre la anemia en hemodiálisis. Diálisis y Trasplante 2005; 26(1):19-26.

13. Kosch M, Schaefer RM: Iron management in renal failure patients-how do we achieve the best results? EDTNA ERCA J 28:182-184, 2002. 